\title{
ОБОЗНАЧЕНИЕ ДВИЖЕНИЯ И НАПРАВЛЕНИЯ ПРИ ОБУЧЕНИИ КИТАЙСКИХ УЧАЩИХСЯ РУССКОМУ ЯЗЫКУ
}

\section{MARKING MOVEMENT AND DIRECTION IN TEACHING RUSSIAN TO CHINESE STUDENTS}

T. Terskikh

Summary: The article considers the formation of skills in the use of Russian verbs of movement, the formation of prefixed verbs of movement and their specific pairs, as well as analyzes errors in the speech of Chinese students and considers ways to prevent them, also draws attention to the polysemy of some verbs of movement. The article focuses on the development of analytical thinking of students for the analysis of the contextual use of verbs of movement. The difficulty of mastering the verbs of movement corresponds to the First certification level.

Keywords: movement, verbs of movement, prefixed verbs of movement, perfect and imperfect form of the verb, context, analysis, thinking.
Терских Татьяна Филипповна

К.филол.н., дочент, Байкальский государственный университет (Иркутск) tirskich@mail.ru

Аннотация: В статье рассматривается формирование навыков употребления русских глаголов движения, формирование приставочных глаголов движения и их специфических пар, а также анализируются ошибки в речи китайских студентов и рассматриваются способы их предотвращения, также обращается внимание на многозначность некоторых глаголов движения. В статье основное внимание уделяется развитию аналитического мышления студентов для анализа контекстуального употребления глаголов движения. Сложность овладения глаголами движения соответствует Первому сертификационному уровню.

Ключевые слова: движение, глаголы движения, приставочные глаголы движения, совершенный и несовершенный вид глагола, контекст, анализ, мышление.

глаголы: идти, ехать, лететь, плыть, бежать, вести, везти, нести, ступить, катить, лезть, ползти, шагнуть, прыгнуть. К глаголам разнонаправленного движения относятся глаголы: ходить, ездить, летать, плавать, бегать, водить, возить, носить, ступать, катать, лазать, ползать, шагать, прыгать.

Глаголы движения однонаправленные и разнонаправленные без приставок (типа идти-ходить) и приставочные вызывают у иностранных учащихся на начальном этапе большие затруднения, которые происходят по разным причинам.

Во-первых, в других языках нет того разграничения характера движения, которое имеется в мышлении носителя русского языка: идти-ходить 'двигаться пешком'; ехатьездить 'двигаться с помощью транспорта, животных'.

Во-вторых, в русском языке наблюдается необычный для языкового сознания людей многих национальностей способ выражения этими глаголами обстоятельственных отношений.

В-третьих, в других языках отсутствует разграничение движения на однонаправленное и неоднонаправленное, повторяющееся и однократное.

Учащиеся сталкиваются с известными трудностями и при построении высказывания с приставочными глаголами движения. 
При отборе глаголов движения следует учитывать и частотность их употребления русскими. Анализ частотных словарей русского языка показал, что многие глаголы движения имеют весьма малую распространенность (плыть, лететь-летать, везти возить, водить, перенести, выехать, отходить и многие другие).

Кроме того, существует, как нам кажется, прямая зависимость частотности слова в речи носителя языка с частотностью этого слова в речи изучающего язык: чем ниже частотность слова в речи носителя языка, тем она будет ещё более низка в речи иностранца.

На начальном этапе обучения могут быть легко и естественно усвоены и активно использованы в коммуникации следующие глаголы движения:

1. бесприставочные глаголы несовершенного вида: идти-ходить, ехать-ездить; факультативно: бежать, лететь, нести;

2. приставочные глаголы группы идти: пойтu, nрuходить-прийти, выходить -выйти, входить-войти, уходить-уйти, подходить-подойти; факультативно: сходить, съездить-пойти, поехать;

3. приставочные глаголы группы ехать: nоexamb, приезжать-приехать, уезжать-уехать, доехать;

4. другие глаголы: привезти, принести.

Конечно, предложенный список глаголов движения нельзя считать постоянным, в процессе обучения могут возникнуть такие ситуации, которые расширят его.

Однако, как показывает практика, только названные глаголы способны удовлетворить истинные коммуникативные потребности обучающихся на начальном этапе. Включение же других, как правило, порождает мнимую коммуникацию, которая может искусственно стимулироваться преподавателем, но оказывается практически бесполезной, не применимой к повседневной жизни обучаемых.

Рассмотрим глаголы движения без приставок: идти и ехать. Трудности усвоения бесприставочных глаголов движения идти и ехать и ошибки при употреблении их в речи разнообразны. Причин тому несколько.

Начальный этап обучения не дает, к сожалению, возможности довести до сознания учащихся некоторые более тонкие значения однонаправленного движения, которые легко воспринимаются и реализовываются русскими. Например:

а) формально не указывается или неизвестно направление движения: Я видел тебя, ты шёл с девушкой;

б) значение однонаправленного движения может восприниматься русскими не только как прямолинейное, оно может изменять направление на отдельных участках, может проходить с перерывами;

в) с помощью однонаправленных глаголов движения может передаваться как однократное, так и повторяющееся движение, значение повторяемости / однократности может быть обусловлено контекстуально.

Сложность проблемы в том, что при первичном объяснении практически невозможно подать информацию во всем объеме, однако преподаватель должен быть готов ответить на вопросы учащихся по поводу частных случаев употребления глаголов движения (при расширении языковой практики непременно такие вопросы возникают).

Особого внимания преподавателя требует объяснение случаев употребления времен рассматриваемых глаголов в пределах ситуаций, изучаемых на подготовительных факультетах.

Форма сложного будущего времени глаголов идтu, ехать употребляется в речи русскими довольно редко. Можно выделить контексты, в которых возможно его употребление:

1. будущее сложное наблюдается при желании указать на длительность движения: Долго мы будем eщё ехать?

2. Оно также может употребляться, если говорящий обращает внимание на различные обстоятельства, сопутствующие движению:

- Я буду идти прямо, вы меня увидите;

- Когда мы будем идти в театр, я покажу вам памятник Гоголю.

Так как коммуникативные задачи начального обучения требуют использования будущего времени в основном значении - передавать предстоящее время, то следует дать учащимся указание, что для выражения такого времени в русском языке существуют глаголы с приставкой по- (nойти, noexamb), не вдаваясь в тонкости употребления форм будущего сложного.

Конечно, по мере расширения речевых ситуаций возникает необходимость в употреблении и будущего сложного в тех условиях общения, о которых шла речь выше, и преподавателю придется сделать необходимые уточнения; однако, в основном слушатели используют в течение всего процесса обучения формы будущего простого, и тренировке употребления этих форм уделяется большое количество времени.

Объяснение начинательного значения должно строиться на специально подобранных примерах, аналогичных данным. При анализе важно обратить внимание на законченность действий, предшествующих движению 
(отдохнуть, купить - глаголы совершенного вида результативного значения), и на способ выражения перехода от законченного действия к движению (nойти, поехать - однонаправленные глаголы совершенного вида с приставкой по- начинательного значения).

Типичные ошибки в речи учащихся можно предотвратить с помощью обязательного анализа каждого из примеров:

- Я взял книгу и пришёл в библиотеку; вместо: - Я взял книгу и пошел в библиотеку;

- Когда занятия кончились, я приехал домой; вместо: - Когда занятия закончились, я поехал домой.

Для предупреждения этих ошибок полезно сообщить следующее: в контекстах, где перечисляется ряд последовательно повторяющихся действий, по нормам русского языка следует употреблять глаголы с приставкой по- (для ряда языков эти глаголы соответствуют по значению глаголам отправиться, направиться).

Объяснение нужно сопровождать большим количеством текстов, которые помогут учащимся соотнести значение русских глаголов пойти, поехать с глаголами родного языка и сделать необходимую коррекцию.

Словообразовательный анализ показывает, что приставка придает мотивирующему слову дополнительное значение: движение к объекту, движение от объекта, движение мимо объекта, сквозь объект и т.д.

Обратим внимание на значение приставок в русских глаголах движения.

Сначала рассмотрим глагольные приставки с антонимичным значением.

Для более легкого усвоения значений приставочных глаголов движения можно сгруппировать слова с антонимичными приставками.

1) Приставки в- и вы- (войти в аудиторию - выйти из аудитории), имеющие значение движения внутрь и соответственно изнутри.

- В последний момент я вбежал в поезд метро.

Приставка в- употребляется с глаголами движения при обозначении подъёма или движения внутрь пространства. - Мимо меня в класс вбегали первоклассники.

Приставка вы- употребляется с глаголами движения при обозначении движения изнутри чего-то: выйти из дома, непродолжительного движения: выйти ненадолго или пересечения какой-либо границы: выехать на дорогу. - Мы выехали из дома в пять часов.
2) Приставки при- и у- (приехать домой - уехать из дома) обозначают приближение к объекту, совершение результативного действия - удаление от объекта.

Приставка при- указывает на конец движения: приехать в гости, и не употребляется с глаголами брести/ бродить, лезть/лазать.

Приставка у- указывает на продолжительное по времени удаление от чего-либо: уехать в отпуск, и не употребляется с глаголами брести/бродить, лезть/лазать. - От других ты убежать можешь, но от самого себя нет. - Извини, но сейчас я не могу с тобой говорить, убегаю в университет.

3) Приставки от- и под- (отплыть от берега - подплыть к берегу) имеют антонимичное значение - удаление на малое расстояние - приближение к предмету, объекту на малое расстояние.

Глаголы движения с приставкой под- (подо- с глаголами идти, гнать) обычно употребляются в сочетании с предлогом к.

Глаголы движения с приставкой om- (omo- с глаголами идти, гнать) употребляется в сочетании с предлогом om с существительными, отвечающими на вопрос откуда? - Подойти, пожалуйста, ко мне.

- Посмотри: человек, который подходит к киоску, Павел Викторович.

- От группы студентов отошёл молодой человек и протянул мне конверт. - Чем дальше, тем больше мы omходим от старых привычек.

3) Приставки с- и раз- (гости съехались на праздник - гости разъехались по домам) обозначают движение из разных мест в одно и соответственно из одного места в разные стороны. - На этом месте в прошлом году товарный поезд сошёл с рельсов. - Друзья разъехались по домам.

Также более результативными были занятия, на которых использовались глагольные приставки, близкие по значению.

Приставки из- и об- близки в значении интенсивности движения (объездить пол-Европы - изъездить полмира).

Приставки за- и у- в значении удалиться, углубиться также могут быть взаимозаменяемы (удалиться в лес зайти в лес).

Глаголы движения с приставками пере- , nро- передают общее значение движения сквозь, через объект (переехать через мост - проехать по мосту). 
Глаголы с приставками под-, npu-, до- передают общее значение приближения. Под- обозначает приближение к определенному объекту (поезд подъехал к перрону), приставка при- обозначает наличие лица или предмета в назначенном месте (поезд прибыл на станцию), глаголы движения с приставкой до- имеют значение достижения предела (дойти до дома, долететь до Москвы).

Глаголы с приставками от-, y- имеют общее значение удаления. Разница в том, что приставка у- имеет значение полного удаления, приставка от- удаление на небольшое расстояние. Часто это подкрепляется лексически (Только отъехал от остановки. Уехал навсегда).

Приставки в- , вз- передают значение движения вверх (влезть на дерево, взойти на вершину). Приставка вз- тяготеет к книжному стилю.

Какие трудности встречаются учащимся при изучении глаголов движения и каковы пути устранения типичных ошибок в употреблении русских глаголов движения?

Причин возникновения трудностей и устойчивых ошибок в речи учащихся, для которых русский язык является иностранным, достаточно много, поэтому при изучении глаголов движения и предлагаются некоторые методические рекомендации для профилактики и устранения ошибок.

Сопоставительное изучение способов выражения значения движения в русском языке даёт возможность прогнозировать основные трудности в изучении и усвоении этой группы глаголов носителями русского языка. Проведённый нами анализ ошибок, допускаемых иностранными учащимися при использовании глаголов движения (позволил классифицировать ошибки по следующим типам.

1. Смешение глаголов, обозначающих разные способы движения (идmu, ехать), то есть внутри группы:

- Мы идём в Москву (вместо: едем).

- Я пойду на Байкал (вместо: поеду).

- Он несёт сестру на ёлку (вместо: ведёт).

Ошибки вызваны интерферирующим влиянием русского языка, в котором глаголы по способу движения не дифференцируются. Устойчивость ошибок может быть также результатом того, что глагол идти долгое время является единственным известным учащимся глаголом движения, а глагол ехать вводится значительно позднее. Следовательно, целесообразно семантизировать оба глагола на одном занятии, подчёркивая оппозицию в значении по характеру перемещения, а в случае затруднений учащихся использовать вопрос-помощник: Пешком или на транспорте?
Понять разницу в значении глаголов идти, ехать помогут также наглядные схемы или схематические рисунки.

Распространённой ошибкой является также подмена глаголов разнонаправленного движения глаголами однонаправленного движения (идтu---ехать), то есть смешение группы глаголов:

- Каждое воскресенье мы идём в кино (вместо: ходим).

- Вчера я шёл в театр (вместо: ходил).

В китайском языке глаголы не дифференцируются по характеру направленности движения, поэтому уже при первом знакомстве с глаголами группы идтu, ехать следует подчеркнуть направленность в одну сторону.

Анализ устных высказываний показал, что китайские учащиеся редко используют в своей речи формы типа ходил, ездил, которые характеризуются высокой частотностью употребления в русском языке, предпочитая вместо этого пользоваться известным им глаголом был.

Если это и не приводит к ошибкам, но значительно обедняет речь учащихся. Кроме того, учащиеся ошибочно используют вместо глаголов ходил, ездил менее употребительные в русском языке формы прошедшего времени шёл, ехал.

Следовательно, на начальном этапе обучения нецелесообразно уделять много внимания упражнениям с глаголами однонаправленного движения в прошедшем времени. Более рационально после объяснения дифференциальных признаков значения глаголов идтu, ехать дать однородный «временной» лексический ряд глаголов: для обозначения действия в настоящем, прошедшем и будущем времени: я иду, ходил, пойду, а форму ходил ещё и для обозначения единичного движения «туда-обратно» с пребыванием в указанном месте.

Глагол ходил заслуживает особого внимания, требует подробного толкования его значения и большого числа тренировочных упражнений, поскольку опорные китайские эквиваленты, которые используются для передачи значения этого слова, сами не содержат указания на движение «туда-обратно.

В случае неправильного выбора глаголов из пары идти-ходить рекомендуется использовать вопрос-помощник: Сколько направлений?

Навык правильного употребления изученных непереходных глаголов идти, ехать; идmu, ходить, examb, ездить переносится затем на усвоение переходных глаголов нести-носить; везти-возить, которые также различаются по способу передвижения (нести, вести, везmu) или по характеру направленности (нести-носить и 
т. д). При этом необходимо заострить внимание учащихся на положении объекта относительно субъекта, используя вопрос-помощник: Где находится объект?

Следует отметить, что учащиеся часто путают глаголы движения из-за слабой фонетической дифференциации. Чтобы помочь им различать, например, глаголы везти, вести и научить правильно употреблять их в письме, нужно подсказать, что реальное движение на транспорте сопровождается звуком, а эта буква имеется в глаголах, значение которых связано с транспортом ездить, возить.

К числу типичных ошибок относится нарушение синтаксической и лексической сочетаемости при использовании глаголов движения:

- Он едет с автобусом (вместо: на автобусе).

- Я еду с машиной на Байкал (вместо: на машине).

- Он приехал велосипедом (вместо: на велосипеде).

- Он ходил у друга (вместо: к другу).

Ошибки этого типа являются результатом интерференции и сигнализируют о недостатках технологии обучения.

Для предупреждения ошибок типа ехать с автобусом необходимо, чтобы предложнопадежные формы на автобусе, на поезде вводились и затренировывались одновременно с глаголом ехать - по аналогии с формами: на столе, на окне, так как обычно к этому времени учащиеся уже знакомы с предложным падежом.

На наш взгляд, ошибки типа ехать с автобусом являются также следствием того, что изучение творительного падежа в школах начинается со значения совместности (работать с Иваном, играть с Сянжуем), а не с инструментального значения (писать карандашом), тогда как обучать китайских учащихся более целесообразно, начиная с инструментального значения творительного падежа, поскольку для их родного языка характерно беспредложное глагольное управление.

С целью профилактики ошибок типа:

- Он ходил у друга;

- Он ходил в музее, следует рассматривать глагол ходил, учитывая его управление, в сочетании с существительным: ходил к кому? к другу; ходил куда? в музей, так как ошибка возникает под влиянием управления синонимичного для данных ситуаций глагола был (был у друга; был в музее). Только после этого глагол ходить целесообразно противопоставить глаголу идти с точки зрения лексического значения характера направленности.

Например:

- Он идёт в музей. Он ходил в музей.

- Он идёт к другу. Он ходил к другу.
Характерная ошибка, допускаемая китайскими учащимися, - неправильное употребление приставок в глаголах движения:

- Завтра я пойду к тебе (вместо: приду).

- По дороге домой я вошёл в магазин (вместо: зашёл).

- Мы ушли от дома (вместо: отошли).

Если глаголы движения без приставок усвоены прочно, усвоение приставочных глаголов проходит с меньшим напряжением, так как ряд трудностей уже снят.

Предупреждению ошибок в употреблении глаголов движения с приставками способствуют схемы-модели, иллюстрирующие их значение. Чтобы схемы-модели стали понятны учащимся, они должны быть расшифрованы.

Так, значение глагола войти передаётся схематическим изображением, где стрелка короткая (субъект только пересекает границу).

Значение приставки по- (пойти) изображается длинной линией как бы в перспективе, а короткая стрелка в начале линии обозначает начало движения.

При изображении значения глагола с приставкой под(о) стрелка только касается границы квадрата, а полукруг обозначает движение с небольшого расстояния.

В сознание и память учащихся с самого начала введения глаголов движения должны «впечататься» определённые схемы-модели, соответствующие тому или иному значению глагола.

Необходимы единые схемы-модели для всех учебных пособий по русскому языку, которые используются в настоящее время. Они должны последовательно распределяться в соответствии с вводом глаголов движения в текстах уроков.

Таким образом, иностранные учащиеся должны знать, что в русском языке глаголы движения различаются как глаголы однонаправленного действия, (действие в одну сторону), и глаголы неоднонаправленного действия или повторяющегося действие (ходить, бегать, летать, плавать, носить, возить, катать, ползать...).

Глаголы движения также имеют вид. Результат движения или процесс движения в русском языке отражен в категории вида (совершенный - несовершенный), движение ненаправленного и направленного действия в русском языке обозначается приставками мотивированного глагола.

В русском языке приставки в глаголах значимы, в каждом конкретном случае приставки в глаголах движения меняют значение глагола. В зависимости от значения приставки, глагол приобретает новое значение: 
местонахождение или направление предмета (субъекта) относительно объекта. Большую роль играет лексический фон, который помогает определить, уточнить необходимые характеристики движения.

Необходимо признать, что в учебниках и учебных пособиях отсутствует минимум теоретических сведений о морфологических, функционально-семантических особенностях глаголов движения, способству- ющих сознательному их усвоению, мало внимания уделяется контекстуальным значениям однонаправленных и ненаправленных глаголов движения, отсутствуют текстовые упражнения, позволяющие проанализировать функционирование глаголов движения, а также отсутствует теоретический и практический материал о видовых особенностях приставочных глаголов движения.

\section{ЛИТЕРАТУРА}

1. Аверьянова А.И. Глаголы движения-перемещения в современном русском языке // Учен. зап. Ленингр. гос. ун-та. - Ленинград: Изд-во Лгу, 1973.Вып.77. - С. 3-11.

2. Барыкина А.Н, Добровольская, В.В. Мерзон С.Н. Изучение глагольных приставок / А.Н. Барыкина, В.В. Добровольская, С.Н. Мерзон. - Русский язык. $1989,-32$ c.

3. Белякова Н.Н. Как строится русский глагол? / Н.Н. Белякова. - Санкт-Петербург: «Златоуст», 2002.

4. Битехтина Г.А, Зелинская Е.А. По-русски без ошибок / Г.А. Битехтина, Е.А. Зелинская. - Москва, 1995.

5. Битехтина Г.А., Юдина Л.П. Глаголы движения с приставками // Русский язык за рубежом, 1978. - №4.- С. 22 - 32; №5. - С. 35-44; №6. - С.24-34.

6. Битехтина Г.А., Юдина Л.П. Система работы по теме «Глаголы движения»/ Г.А. Битехтина, Л.П. Юдина. - Москва: Рус. яз., 1985. -160с.

7. Бондарко А.В. Грамматическое значение и смысл / А.В. Бондарко. - Москва, 1978.

8. Бондарко А.В. Принципы функциональной грамматики и вопросы аспектологии. - Ленинград: Наука, 1983. - 208 с.

9. Бондарко А.В. Функциональная грамматика. - Ленинград: Наука, Л0, 1984. - 136 с.

10. Виноградов В.Д. Лингводидактические основы обучения русскому языку и культуре речи: Сб. избранных статей и докладов / В.Д. Виноградов - Н. Новгород: Изд-во НГПУ, 2001. - 165 с.

11. Глазунова 0.И. Грамматика русского языка / 0.И. Глазунова. - Санкт-Петербург: «Златоуст», 2003.

12. Глаголы движения как объект современных лингводидактических исследований URL: https://vuzlit.ru/945729/glagoly_dvizheniya_obekt_sovremennyh_ lingvodidakticheskih_issledovaniy (дата обращения: 11.06.21).

13. Зализняк А.А. Грамматический словарь русского языка. Словоизменение / А.А. Зализняк. - Москва, 1977.

14. Иевлева 3.Н. Методика преподавания грамматики в практическом курсе русского языка для иностранцев / З.Н. Иевлева. - Москва, 1981.

15. Кондрашевский А.Ф. Практический курс китайского языка / А.Ф. Кондрашевский. - Т.1, Т.2. - Москва : «Муравей», 2001.

16. Костомаров В.Г, Митрофанова О.Д. Методическое руководство для преподавателей русского языка иностранцам/ В.Г. Костомаров, О.Д. Митрофанова. Москва: «Русский язык», 1982.

17. Кривоносов А.Д, Редькина Т.Ю. Знаю и люблю русские глаголы. - Санкт-Петербург: «Златоуст», 2002.

18. Корчик Л.С. Глаголы движения в русском языке и особенности их преподавания в китайской аудитории. URL: https://socionet.ru/publication.xml?h=spz:cy berleninka:23357:14286116

19. Ниматулаева М.Д. Методические аспекты преподавания глаголов движения иностранным студентам URL: https: //cyberleninka.ru/article/n/ metodicheskie-aspekty-prepodavaniya-glagolov-dvizheniya-inostrannym-studentam (дата обращения: 12.06.21)

20. Теория грамматического значения и аспектологические исследования / А.В. Бондарко, Ю.С. Маслов, В.М. Павлов и др. / Отв. ред. А.В. Бондарко. - Ленинград: Наука, Л0,1984. - 280с.

21. Толковый словарь русского языка: В 4 т. : / Под ред. Проф. Д. Ушакова.- М.: TEPPA- Книжный клуб, 2007. 752 c. URL:https://ru-dict.ru/slovar-ushakova.html (дата обращения: 16.02.21).

22. Фен Мин Сен 范明贤. Современный китайско-русский словарь.外语教学与研究出版社. - Пекин, 2002.

23. Чжо Вэнуан (赵文炎). Новый русско-китайский словарь. - Пекин: Изд-во «Иностранные языки», 1992. 